\title{
Interesting Facts about the History of Diabetes Mellitus
}

\author{
Oscar J. Garza-Ovalle ${ }^{1}$, Adrián Garza-Ovalle ${ }^{2}$ and Jesús Fernando Ovalle-Berumen ${ }^{3}$ \\ ${ }^{1}$ Division of Cardiology, University of Chicago NorthShore, Evanston, IL 60201, USA; ${ }^{2}$ Department of Internal Medicine, School of Medicine, \\ Universidad de Montemorelos, N.L., Mexico; ${ }^{3}$ Departament of Internal Medicine and Endocrinology, School of Medicine, Universidad Autónoma \\ de Nuevo León, Monterrey, N.L., México
}

Diabetes mellitus is a disease that has accompanied humankind probably since the beginning of history. However, we only have written evidence dated back to the year $1550 \mathrm{BC}$; date in which the "Ebers Papyrus" was written ${ }^{1}$ (Fig. 1). This document was found in tomb excavations near the city of Thebes. The papyrus measures $20.2 \mathrm{~m}$ long and $30 \mathrm{~cm}$ wide, and it remains very well preserved. The papyrus contains the first known medical reference to diabetes.

In this article, we do not pretend to provide an exhaustive description of the history of diabetes, but only to recollect a series of interesting and entertaining facts that demonstrate that with time, patience, and with human intelligence and ingenuity, sometimes with the help of luck or by mere chance, the knowledge about this disease has been gradually built. We believe that this is how knowledge about science, in general, is formed and augmented. The historical facts contained in this article are presented in chronological order and range from ancient times to the mid- $20^{\text {th }}$ century. The understanding of diabetes continues to be an evolving process up to modern days. Diabetes ("Siphon" in Greek) refers to one of the most common symptoms of the disease: Excessive urine production or polyuria.

After the "Ebers Papyrus" a long time elapsed, until the year $400 \mathrm{BC}$ when Hippocrates was the first to provide a detailed description about the amputation of a lower extremity on a patient who most likely had diabetes. He described it with the following words: "a painless amputation of a gangrenous extremity, with little or no bleeding." In the year $270 \mathrm{BC}$, Demetrius of
Apamea used the denomination DIABETES, which meaning according to him was "to go or run through." He explained that in people who suffered from the disease, the liquid does not remain in the organism but only "goes through" it immediately after its oral intake (like passing through a tube). Celsus (25 BC- $50 \mathrm{AD}$ ) in his work "De Medicina" summarized the knowledge of diabetes of his epoch and he already acknowledged the two fundamental principles in the treatment of the disease: Diet and physical activity? ${ }^{2}$.

The classical description of this health problem came from Aretaeus of Cappadocia in the second century AD: "Diabetes is a remarkable affliction... Being a melting down of the flesh and limbs into urine, for the patients never stop making water, but the flow is incessant, as if from the opening of aqueducts. The nature of the disease is chronic, and it takes a long period to form; but the patient does not live long once the disease is fully established; for the melting is rapid, the death speedy. Moreover, life is disgusting and painful..." J.O. Baptiste Morgagni wrote: "Diabetes est morbus in sede incerta." "Diabetes is a disease of unknown location" (Fig. 2).

In 1674, the English anatomist Thomas Willis issued the hypothesis that diabetes is due to "Dietary deficiencies." Johann Conrad Brunner (1653-1727) was a general practitioner in Basel and eventually a professor at Heidelberg University. He was the first to report a case of "Transient diabetes" in a dog after partial pancreatectomy. In 1776, the British Matthew Dobson reported that "the sweet taste of urine" is due to the presence of sugar (Fig. 3).

\section{Correspondence:}

Jesús Fernando Ovalle-Berumen

E-mail: jovalle370228@yahoo.com

DOI: 10.24875/RMU.M18000025
Available online: 30-11-2018

Date of reception: $28-08-2018$

Date of acceptance: 18-09-2018
Medicina Universitaria. 2018;20(3):136-139

www.medicinauniversitaria.org CC BY-NC-ND license (http://creativecommons.org/licenses/by-nc-nd/4.0/) 


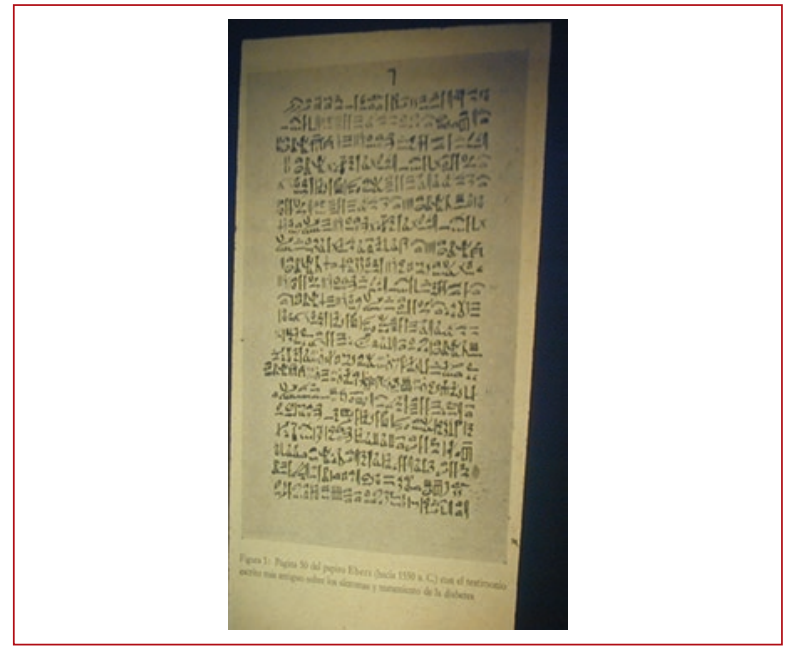

Figure 1. Here is a photograph of page 50 of the original "Ebers Papyrus".

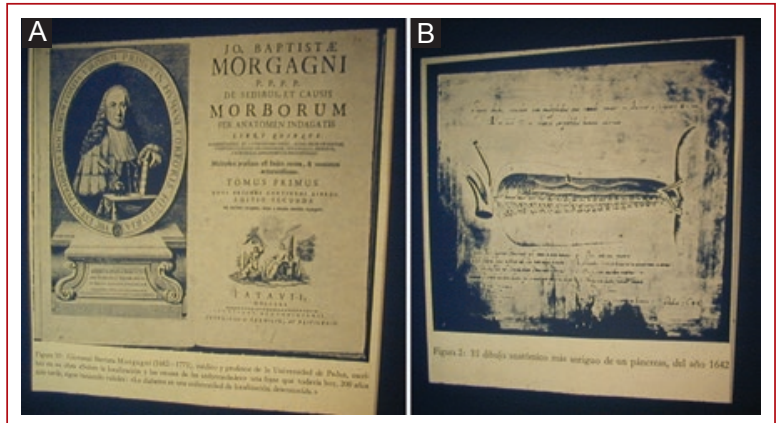

Figure 2. $(A$ and $B)$ Here are the covers of the book written by J.0. Baptiste Morgagni (left) and the first schematic drawing of the pancreas; which dates back to 1642 AD (right).

William Cullen (1712-1790) established for the $1^{\text {st }}$ time the difference between diabetes mellitus and diabetes insipidus. In 1794, the German Johann Peter Frank introduced the term "mellitus" (of or pertaining to honey), to differentiate from diabetes insipid us $^{4}$. In 1797 and 1798, John Rollo recommended for the $1^{\text {st }}$ time the restriction of carbohydrates in the treatment of patients with diabetes. W.H.W. was a famous chemist and a physician at London's Guy's Hospital. In 1811, he developed a method for the measurement of glucose in blood; however, it did not record levels below $600 \mathrm{mg} /$ dl. Reason for which he later published that: "There is no glucose in the blood." The Frenchmen Bouchardat and Peligot demonstrated in 1838 that the sugar in diabetic urine was actually glucose ${ }^{5}$. In 1840, Trommer

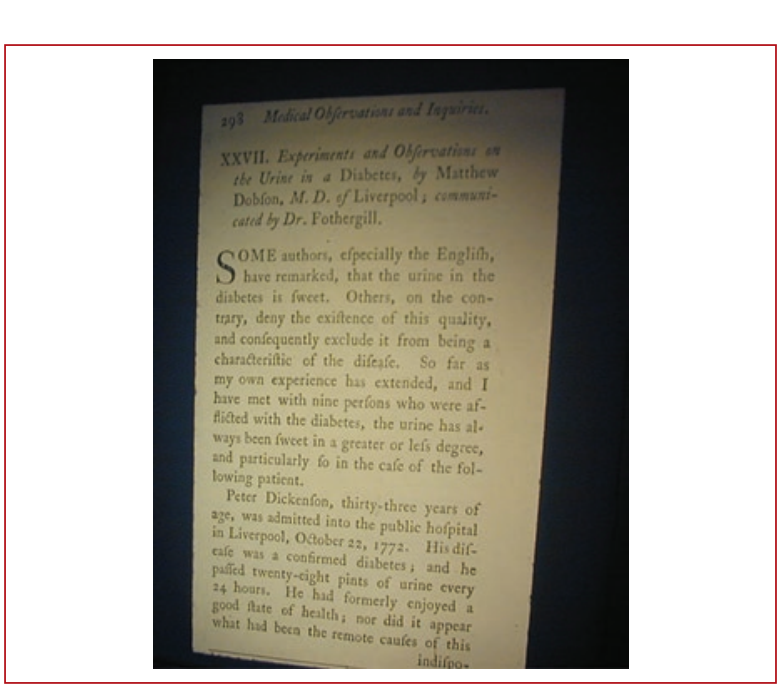

Figure 3. Here is page 298 of the journal Medical Observations and Inquires, which describes Dobson's experiments with the urine of diabetic patients.

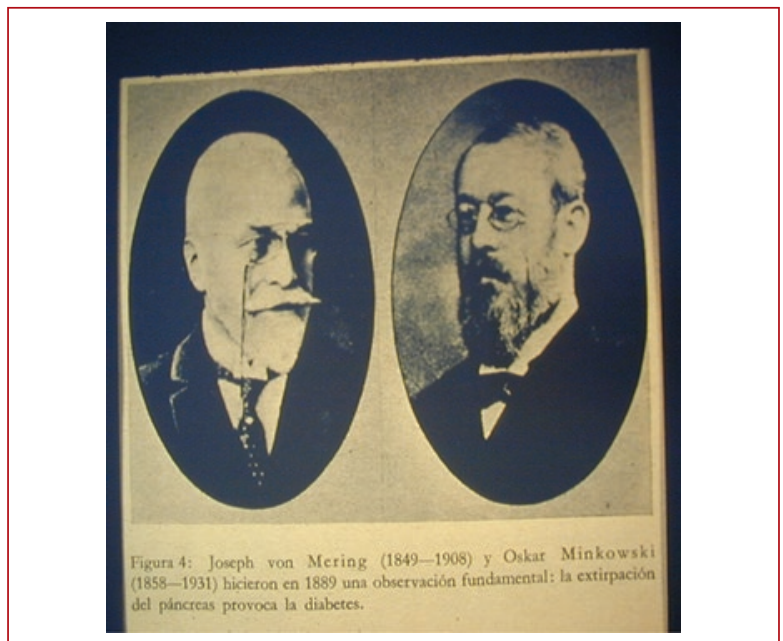

Figure 4. Here are photographs of Minkowsky (Left) and Von Mering (right).

developed a test that analyzed the content of sugar in urine. In 1848, Hermann Von Fehling expanded on this prior invention by developing a quantitative test. In 1841 Carl August Trommer, in 1844 Johann Florian Heller, and in 1850 Hermann Von Fehling performed the first classical tests for the measurement of glucose in the bloodstream. In Prague in the year of 1857, Wilhelm Petters (1820-1875) noted that in the urine and the expired air of a person with severe diabetes, there was a strange smell like violets. Peters assumed that this was due to the presence of acetone; to prove it, he collected 


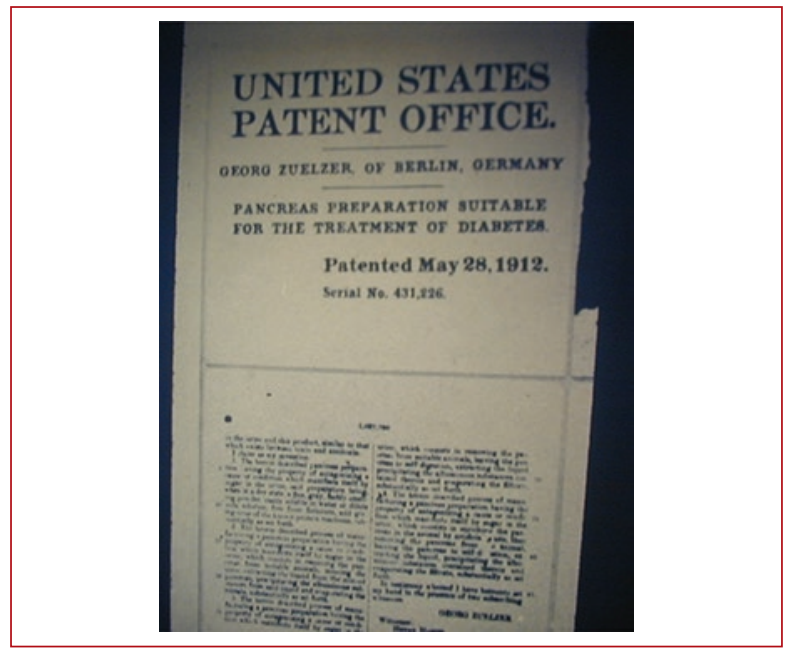

Figure 5. Here is a photograph of the Zuelzer's attempt to patent a preparation for the treatment of diabetes in the United States Patent Office in 1912.

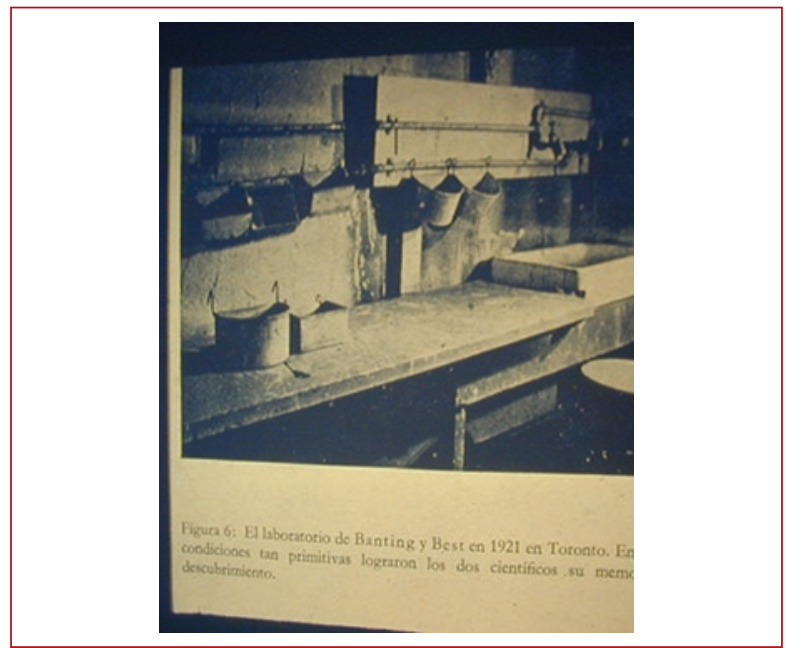

Figure 6. Photograph of a section of the laboratory where Banting and Best performed their research. Note the precarious condition of their equipment.

$700 \mathrm{~L}$ of urine from diabetic patients. He was able to obtain acetone from this sample effectively.

Nowadays, it is possible to detect the presence of acetone in the urine, with a very simple procedure which consists of putting a drop of urine on a small tablet, the change of color to violet means the presence of acetone. In 1869, Paul Langerhans discovered a special type of pancreatic cells that grouped themselves in islets. These groups of cells were eventually called pancreatic Langerhans islets. During the siege of Paris in 1871, Apollinaire Bouchardat confirmed that diabetes

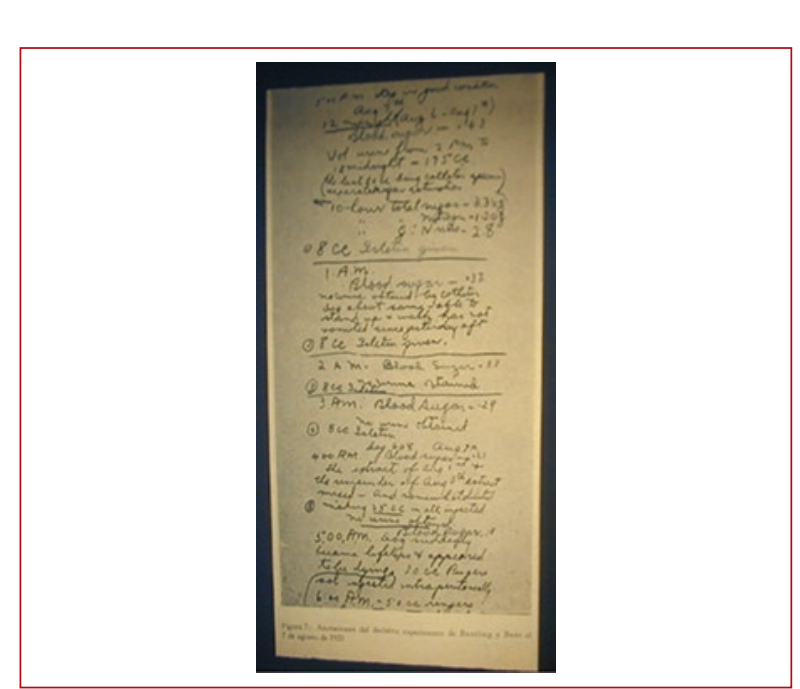

Figure 7. Photograph showing a handwritten sheet of paper with their observations on pancreatectomized diabetic dogs.

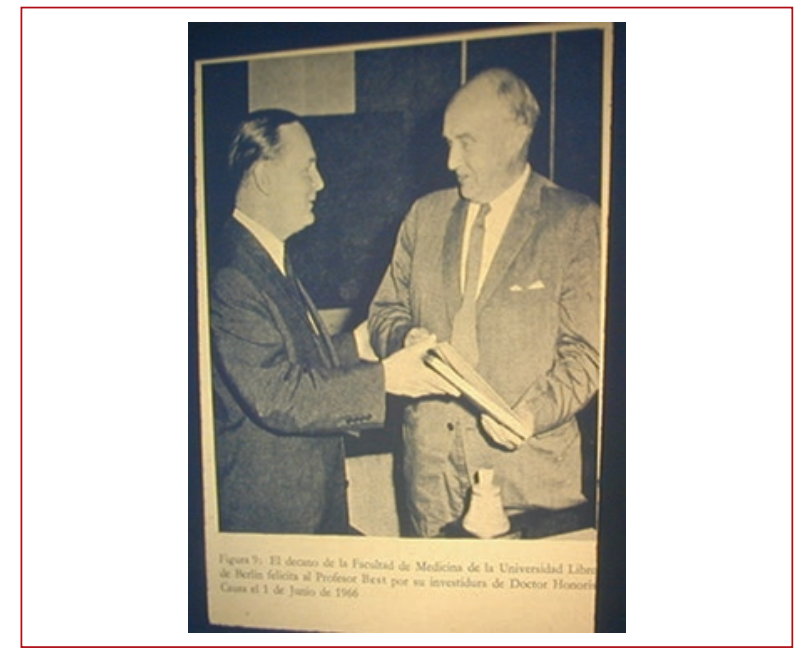

Figure 8. Shown here is a photograph of the Dean of the Medical School of the University of Berlin granting an honorary doctorate degree to Dr. Charles Best in 1966.

improves with decreased caloric intake. In 1889, the German physicians Oskar Minkowsky and Joseph Von Mering discovered by chance that the extirpation of the pancreas resulted in diabetes (Fig. 4).

In 1893, Edouard Laguesse was the first to suspect that the pancreatic cells in Langerhans Islets have endocrine functions. Rudolf Virchow (1821-1902) süggested that the pancreas "secreted something" into the bloodstream. In 1909, the Belgian Jean De Meyer baptized the substance that is produced in the Langerhans Islets with the name of insulin. In 1903, the German 
George Ludwig Zuelzer accomplished to isolate an active preparation from the cells in the Langerhans islets; but due to allergic and toxic reactions to the preparation, he is forced to abandon his research (Fig. 5).

In 1921, the Canadian physiologist Frederick Grant Banting and the medical student Charles Herbert Best, working at the University of Toronto, successfully isolated clinically usable insulin ${ }^{6}$ (Fig. 6 and 7). On January 23 of 1923, insulin was successfully utilized in a 14-year-old patient. In favor of humankind, Banting and Best renounced to their financial rights derived from the mass production of insulin. They were symbolically paid with one US dollar (Fig. 8).

In 1942, the French physician M. Janbon, at Montpellier, reported two deaths from hypoglycemia that resulted after the administration of a sulfonylurea that was synthesized by the German chemist J. Kimmig. H. Frankie and J. Fuchs, working in Berlin in 1954, observed that after administering a new sulfonylurea, a series of secondary effects were seen. Fuchs later identified these effects as a hypoglycemic reaction after experimenting the drug on himself. With Fuchs experience, they decided to employ the new sulfonylurea (carbutamide) for therapeutic purposes in the management of diabetes. They were successful. This is also how an initial undesirable secondary effect evolved until it became the main effect of the medication.

So far we have reunited a long series of peculiar and interesting facts about the fascinating history of diabetes. As we mentioned at the beginning, this recollection was not meant to be exhaustive and more information on the subject exists. History continues to be written on a daily basis. We hope that what we have presented here is of interest to the people that manage diabetes on a daily basis and that it provides a stimulus to increment our knowledge of this widespread disease.

\section{Ethical disclosures}

Protection of human and animal subjects. The authors declare that no experiments were performed on humans or animals for this study.

Confidentiality of data. The authors declare that no patient data appear in this article.

Right to privacy and informed consent. The authors declare that no patient data appear in this article.

\section{References}

1. Ghalioungui P. The Ebers papyrus: a new English translation, commentaries and glossaries. Cairo: Academy of Scientific Research and Technology; 1987.

2. Spivack BS. A. C. Celsus: Roman medicus. J Hist Med Allied Sci. 1991;46:143-57.

3. Laios K, Karamanou M, Saridaki Z, Androutsos G. Aretaeus of cappadocia and the first description of diabetes. Hormones (Athens). 2012;11:109-13.

4. Mann R. Historical vignette "honey urine" to pancreatic diabetes: 600B.C Mayo Clin Proc. 1971;46:56-8.

5. Bouchardat A. De la Glycosurie ou Diabète Sucré. Son Traitement Hygiénique. Paris: Baillière; 1875

6. Banting FG, Best $\mathrm{CH}$, Macleod JJ. The internal secretion of the pancreas. Am J Physiol. 1922;59:479. 